Fanum

Sociológico

\section{Forum Sociológico}

Série II

$24 \mid 2014$

Circulação de saberes e desafios em saúde

\title{
Sofrimento e Silêncio: apontamentos sobre sofrimento psíquico e consumo de psicofármacos
}

Suffering and silence: Notes on psychic suffering and consumption of psychopharmaca

Jonatas Ferreira

\section{OpenEdition}

Journals

Edição electrónica

URL: https://journals.openedition.org/sociologico/1133

DOI: $10.4000 /$ sociologico.1133

ISSN: $2182-7427$

Editora

CICS.NOVA - Centro Interdisciplinar de Ciências Sociais da Universidade Nova de Lisboa

Edição impressa

Paginação: 121-128

ISSN: 0872-8380

Refêrencia eletrónica

Jonatas Ferreira, «Sofrimento e Silêncio: apontamentos sobre sofrimento psíquico e consumo de psicofármacos», Forum Sociológico [Online], 24 | 2014, posto online no dia 01 novembro 2014 , consultado o 30 março 2022. URL: http://journals.openedition.org/sociologico/1133 ; DOI: https:// doi.org/10.4000/sociologico.1133

Este documento foi criado de forma automática no dia 30 março 2022

(C) CICS.NOVA 


\title{
Sofrimento e Silêncio:
} apontamentos sobre sofrimento psíquico e consumo de psicofármacos ${ }^{1}$

\author{
Suffering and silence: Notes on psychic suffering and consumption of \\ psychopharmaca
}

Jonatas Ferreira

1 De acordo com dados do relatório Health at a Glance (2011), de 2000 a 2009, entre os países que compõem a Organization for Economic Cooperation and Development, houve um aumento de $60 \%$ no consumo de antidepressivos ${ }^{2}$. Fluoxetina, Paroxetina, Sertralina, Venlafaxina, Nefazodona, Citalopram, são as grandes protagonistas de uma transformação na psiquiatria. Elas constituem uma geração de psicotrópicos de maior tolerabilidade, cujo efeito mais evidente tem sido a medicalização de emoções antes consideradas aflições aceitáveis, associadas à própria condição humana, ou à vida num contexto de modernização. Esses medicamentos proporcionam a oportunidade de estabilização psíquica num contexto de constante aceleração e consequente geração de ansiedades. Para muitos, o desenvolvimento de uma geração eficiente de psicofármacos parece ter livrado o comum dos mortais de um mal-estar desnecessário.

o homem pedirá à farmacologia [...] a liberação e o desenvolvimento de suas faculdades propriamente humanas. O operário que volta para casa após um dia de trabalho duro e desinteressante, que espera reencontrar um lar demasiadamente estreito, uma mulher cujo trabalho extenuante deixou de humor rabugento, crianças de pouca idade que gritam, [...], passará no caminho da volta num bar e tomará alguns copos de álcool. Ele sabe de fato empiricamente que o álcool o deixa mais indiferente às preocupações que o acabrunham. Ele faz neuropsicofarmacologia sem o saber, utilizando uma droga bem mais tóxica que os tranquilizantes (Laborit apud Ehrenberg, 1995: 33).

2 A citação acima permite tocar em temas importantes: primeiro, a promessa de uma psicofarmacologia capaz de promover o desenvolvimento de "faculdades propriamente 
humanas"; segundo, a constatação implícita de que o sofrimento é desumanizador - o que é uma novidade cultural: basta que nos reportemos ao cristianismo e à tradição trágica para nos darmos conta da importância de uma significação do sofrimento para o humanismo; e, por último, a expectativa de que o medicamento psicoativo em geral possa constituir uma resposta satisfatória ao trabalho rotineiro e tedioso, a uma mulher estressada, a crianças infelizes. Caricatural, esse pequeno relato chama nossa atenção para a força argumentativa de uma indústria que age num espaço cultural deixado aberto pelo colapso de grandes narrativas capazes de mobilizar e dar significado ao sofrimento dos indivíduos. Na citação acima, uma questão cultural parece se impor em meio à constatação do apelo que os psicofármacos passaram paulatinamente a desfrutar nos últimos trinta anos. "Qual o sentido do sofrimento nas sociedades contemporâneas?" E: "Por que sofrer se nosso sofrimento não constitui parte de uma «ascese» razoável, não está a serviço da realização de nenhum conjunto de valores fundamentais?" Essas duas perguntas só fazem sentido se partirmos do pressuposto, como o fazemos, de que dar sentido ao sofrimento humano é um eixo fundamental da organização das culturas.

3 Junto à oportunidade comercial que esses medicamentos representam, uma mudança epistemológica no tratamento do mal-estar psíquico foi promovida sob a égide da psiquiatria estadunidense, particularmente, com a popularização das últimas edições dos Diagnostic and Statistical Manual of Mental Disorders. Esse manual, como sabemos, passou a orientar e regular a prática médica, e não apenas a prática psiquiátrica, no que concerne ao sofrimento psíquico. Mediante a catalogação de um conjunto de sintomas claramente estabelecidos, cardiologistas, ginecologistas, clínicos gerais podem agora chegar a um diagnóstico e a uma terapêutica de base química para diversas formas de ansiedade e tristezas da vida cotidiana. Sob essa nova perspectiva, já não temos em nossa sociedade neuróticos, mas vítimas de transtornos, como o pânico, a depressão, a obsessão compulsiva. No campo médico, os sofrimentos psíquicos já não são prioritariamente objeto de uma terapêutica pela fala, uma terapêutica em que o padecimento possa ganhar significado, mas de um tratamento que prioriza a atenuação de sintomas.

o sintoma é a própria doença ou, mais propriamente, o transtorno mental; a intervenção química nos processos cerebrais substitui ou toma a dianteira sobre o tratamento psicanalítico, isto é, sobre o tratamento pela palavra - em que o paciente era levado reconhecer o seu sofrimento, ou seja, dar-lhe proporção e sentido existencial. Com a popularização das novas terapias de base química dissemina-se uma percepção de que não precisamos dar significado ao nosso sofrimento, mas silenciá-lo radicalmente. $A$ consequência mais radical da privatização do sofrimento é o seu emudecimento, sua transformação em um conjunto de sintomas que podem ser objeto de tratamento bioquímico.

\section{Sofrimento, melancolia e subjetividade}

5 Na sociedade da informação, a única forma de obtermos silêncio parece ser, ele argumenta, a avaria técnica: o computador não funciona, a conexão com a internet caiu, o canal de TV está fora do ar etc. A tagarelice que caracteriza nossos envolvimentos cotidianos, todavia, seria apenas uma evidência de que já não conseguimos verdadeiramente dizer mais nada de significativo. Se pudéssemos calar por um momento talvez viéssemos a constatar precisamente isso: numa cultura em que 
a linguagem é achatada diuturnamente pelos imperativos técnicos da ciência da informação e por um capitalismo que só pode ter uma relação predadora com o mundo, parece que nada temos a dizer. Poderíamos propor, de um modo algo paradoxal, que a impossibilidade de silêncio neste contexto só é possível mediante a garantia de certos silenciamentos, pelo emudecimento de tudo aquilo que venha a comprometer a plena circulação de signos, a aceleração e o consumo. $O$ silenciamento do sofrimento é um desses fenômenos técnicos sem o qual a plenitude do consumo, a aceleração constante não pode ser alcançada. É a partir dessa constatação que podemos compreender a inconveniência da depressão, da melancolia no mundo contemporâneo e, de resto, lançar alguma luz sobre as estatísticas de consumo de medicamentos psicoativos expostas no tópico anterior.

6 Poderíamos afirmar que a analgesia e apatia que marcam a contemporaneidade são plenamente compatíveis com uma cultura do consumo, dos gozos superficiais, da agitação constante da vida e da extenuação dos recursos do planeta (Ferreira e Silva, 2011). Na Dialética do Esclarecimento, Adorno e Horkheimer (1985: 93) discorrem acerca do modo como a cultura moderna impõe uma distância emocional que inviabiliza aquilo que poderíamos chamar, com Benjamin, de experiência. Analisando o significado moral da obra de Sade no mundo moderno, eles afirmam: "«A apatia (considerada como fortaleza) é um pressuposto indispensável da virtude», diz Kant, distinguindo essa «apatia moral» (um pouco à maneira de Sade) da insensibilidade no sentido da indiferença a estímulos sensíveis. $O$ entusiasmo é mau. A calma e a determinação constituem a força da virtude." E, no entanto, vivemos uma realidade de excitação constante, em que uma infinidade de apelos sensíveis nos solicitam diuturnamente e aos quais só podemos atender se não nos comprometermos verdadeiramente com coisa alguma. Acredito que hoje experimentamos o recrudescimento de um traço fundamental dos processos de modernização, marcados que estão pela apatia, analgesia, pelo niilismo.

7 Todas essas evidências devem ser colocadas no contexto de uma discussão mais ampla que diz respeito ao sentido do sofrimento nas sociedades modernas e de uma reflexão acerca de como, ou em que medida, o tratamento com substâncias psicoativas interfere neste processo de significação. $\mathrm{O}$ uso de antidepressivos e ansiolíticos nos coloca sempre diante da perspectiva de um adiamento indefinido de tal processo na exata medida que podemos contornar os sintomas físicos da ansiedade, da depressão, do pânico e de muitas outras afecções. Se, por um lado, a ideia de uma terapêutica para essas e outras formas de sofrimento é tão antiga no Ocidente quanto a própria formalização da prática, de uma techné médica, como pode atestar a leitura de várias das obras que constituem o corpus hipocraticum (Conti, 2007), e a vasta literatura que a segue, a forma como damos sentido ao sofrimento sempre teve um papel fundamental na cultura ocidental. Weber, por exemplo, entende que o problema do sentido do mal no mundo, ou seja, da existência do sofrimento e da morte, é o núcleo sobre o qual as grandes religiões mundiais gravitam. Em outras palavras, as grandes formações culturais que a história da humanidade conhece estariam inextricavelmente relacionadas a processos de significação do mal, do sofrimento humano.

8 Cassirer, outro exemplo relevante, dedica um belo capítulo de seu A Filosofia do Iluminismo (1951) a traçar uma linha de continuidade entre a forma como a tradição judaico-cristã lida com o sofrimento e a sua tradução em discurso e prática científicos, iluministas. Mais contemporaneamente, se tomarmos a fenomenologia de Jan Patocka 
(1996), poderíamos mesmo argumentar que aquilo que fundamentalmente caracteriza a cultura ocidental é o fato de atribuirmos ou buscarmos significado para as experiências que implicam um padecimento moral, existencial - no mais vivemos confortavelmente na atitude natural dos fatos que, por não constituírem um problema, não demandam a busca de significação ampla.

9 A forma como damos sentido ao sofrimento, ou, dito de um modo mais religioso, à presença do mal no mundo, é evidentemente histórica. Faz necessário, pois, especificar a ideia ampla de sofrimento numa noção muito mais precisa e relevante para o argumento deste ensaio: a melancolia. A centralidade de tal noção na estruturação de uma narrativa da subjetividade, ou seja, em uma narrativa que confere significado ao sofrimento moderno como contraponto à possibilidade de liberdade individual, é uma das hipóteses básicas deste ensaio. Digamos com todas as letras: se é inquestionável que a modernidade é marcada por uma metafísica da subjetividade que se legitima por um discurso racionalizador, não é menos verdade que essa razão sobre a qual o sujeito se constitui como entidade moral, epistemológica e técnica, precisa ser experienciada existencialmente. Do contrário, ela seria uma mera abstração sem sentido operativo. É a melancolia que oferece a possibilidade de atar as pontas aparentemente disparatadas do discurso moderno, isto é, sua força estética e diluidora, por um lado, e sua estrutura racional, por outro. A uma conclusão semelhante parece chegar Weber, para citarmos apenas um exemplo, quando fala da ansiedade que caracteriza a ética calvinista, sua insegurança com relação à salvação, como um dos fatores que levam o fiel a abraçar a tarefa e o chamado religioso de racionalização do mundo. A tese weberiana, como veremos, está longe de ser original. Parece-nos que é exatamente uma discursividade melancólica como núcleo simbólico, existencial da subjetividade que parece entrar em crise na contemporaneidade com a emergência da possibilidade técnica de adiar indefinidamente os sintomas do sofrimento. Não parece fortuito, portanto, que essa crise coincida com uma percepção cada vez mais hegemônica da realidade contemporânea como algo estruturalmente irracional.

A palavra "melancolia" deriva do grego, mais especificamente das palavras melaina e chole, cuja tradução seria "bile negra". Derivada do corpus hipocraticum, a teoria dos humores, em cujo contexto a melancolia é explicada a partir do século V a. C., é uma teoria do equilíbrio entre o ser humano e o cosmos. Se nos ativermos a essa ideia, que encontraremos de variadas formas na Estética ou na Política de Aristóteles, nos Aforismos de Hipócrates, na matemática de Pitágoras, ela se traduz sempre em um sentido ontológico que conecta todos os seres e se manifesta sob a forma de ideal estético, moral, político ou como dietética e terapêutica. Por isso mesmo, os elementos básicos que ditam nossa saúde ou nossas enfermidades, os traços de nossa personalidade ou estrutura física, regulam também as estações do ano, as fases da vida. E isso por um motivo simples, o ser humano é considerado parte da natureza - ou, mais propriamente, da physis. Deste modo, o sangue é associado tanto à primavera, quanto ao calor e a umidade, ou à infância dos seres humanos; a bile amarela é associada ao verão, ao calor seco e à vida adulta; a bile negra ao frio seco, ao outono e ao ocaso de nossa vida; a fleuma à velhice, ao inverno e à umidade fria (Conti, 2007: 16). Para a medicina grega, a melancolia é entendida como desequilíbrio nos humores em que prevaleceria a força da bile negra - quer esse desequilíbrio ou predomínio seja um traço de personalidade, uma afeç̧ão passageira ou uma doença - em cujo caso o retorno a um estado de equilíbrio demanda a intervenção médica, uma dieta, medidas profiláticas. A influência da teoria dos humores prolonga-se dos gregos até a Idade Moderna. Não 
obstante importantes reelaborações, e mesmo contestações, ela segue mantendo vivo um ideal de proporção e equilíbrio entre o corpo humano e a ordem cósmica.

11 Tomado geralmente como acédia, como incapacidade do espírito em decidir, a visão prevalecente que a Idade Média oferece da melancolia é que ela é um pecado: tratava-se de um monstro que lança confusão, preguiça, imobilidade, observa Evagrius Ponticus, "o solitário" (Ferguson, 2005: 7). Em todo caso, a partir do século XII, "a partir das decisões dos Concílios de Clermont e de Letrán" que proibiu os monjes de prestar assistência médica aos enfermos fora dos muros dos mosteiros, uma secularização da medicina sobreveio (Conti, 2007: 37). E, assim, o humanismo de Marsilio Ficino, no século $\mathrm{XV}$, pôde retornar confortavelmente à visão positiva que Platão tinha deste sentimento. "Aqueles sob a influência de Saturno tendem para a melancolia, e, de acordo com Ficino, isto não é sempre um infortúnio. Revivendo as visões de Platão, Ficino percebe a melancolia como um dom intelectual, que por seu turno estimula dois outros frenesis divinos, a poesia e a filosofia" (Ibid.: 9). No século XVI, Teresa de Ávila parece entender a melancolia como espaço tanto de manifestação do divino quanto do diabólico no ser humano. Para ela, seria necessária certa sutileza de espírito para diferenciar o sofrimento melancólico da angústia provocada por Deus quando este “incendeia o espírito" (Radden, 2000: 108). Esta fineza de espírito é precisamente a capacidade de entender se somos tomados por um sofrimento da alma ou da imaginação, ou seja, uma dor presidida por Deus ou pelo demônio.

12 Aquilo que chamaríamos de sensibilidade barroca em Teresa de Ávila é um passo decisivo para a estruturação de uma ideia moderna de melancolia. Primeiro, Teresa diferencia de modo pragmático aquilo que hoje denominaríamos comportamentos neuróticos mais brandos daqueles que poderíamos chamar de casos psicóticos mais graves. No tratamento destes, recomenda a tolerância; no tratamento dos primeiros, o uso da autoridade. É de se observar que a aceitação dessa autoridade é um fator crucial no processo de cura da melancolia. O foco das considerações de Teresa de Ávila tem um caráter já fortemente psicológico, se o comparamos com a teoria dos humores. $\mathrm{O}$ que chama atenção no seu Livro da Vida, por exemplo, é o fato de suas dúvidas, indecisões e sofrimentos não poderem ser aliviados pela voz da tradição, mas apenas por uma experiência única e mística com a autoridade Divina. Isso que chamamos de sensibilidade barroca virá a preparar uma virada moderna que nos diz respeito mais de perto: diante do sofrimento, da incerteza, a única promessa de resolução se encontra na graça de Deus. Como melancólica ela raciocina: sou fundamentalmente má. E disso conclui: todo bem me é fundamentalmente alheio, ou seja, proveniente de Deus. Esta é a possibilidade de significação do mal, do sofrimento no mundo. Se a resolução proposta é aqui transcendente, o problema coloca já a subjetividade como questão cultural central. A acédia, a tristitia, portanto, não lhe são estranhas, mas um lugar de onde ela só pode sair a partir da intervenção da autoridade maior da Divindade: "Pois bem sabe meu Senhor que não pretendo outra coisa com isso a não ser que ele seja louvado e engrandecido um pouquinho por ver que, em uma fossa tão suja e malcheirosa, fez um jardim de tão suaves flores" (Teresa d'Ávila, 2010: 103).

Quando lemos Teresa de Ávila e comparamos com tudo o que Benjamin falou acerca do conceito de acédia e da importância do drama barroco alemão como indicadores de um processo de modernização cultural na Europa, impossível não perceber a estatura intelectual desse pensador alemão. A indecisão paralisante de Segismundo, de A vida é Sonho, ou de Hamlet, aguardam, como em Teresa de Ávila, uma decisão, um corte 
transcendente ${ }^{3}$. Tal é a solução barroca, absolutista, para a questão política, cultural e existencial que a modernidade implica. A partir do começo do século XIX, o Romantismo levou adiante o namoro platônico entre melancolia e sensibilidade artística, além de associá-las ambas ao próprio frenesi da vida moderna. Mais recentemente, isto é, com a elaboração de um sistema de classificação de doenças mentais por Emil Kraepelin, ela passou a ser considerada doença, com um conjunto de sintomas delimitados, identificáveis: despersonalização, impressão de que o mundo se tornou estranho, de que o próprio corpo é sentido como algo apartado do indivíduo etc. (Radden, 2000: 261). Em Kraepelin encontramos a base da psiquiatria estadunidense que hoje prevalece como terapêutica no mundo e a tentativa de proceder a uma classificação rigorosa das doenças mentais, o que conduziu a uma definição mais precisa do conceito de melancolia.

Acredito que o sofrimento, em particular a melancolia, na cultura moderna é um lugar privilegiado para observar as implicações existenciais, mas também políticas e sociais, que decorrem do que podemos alternativamente chamar de empobrecimento da experiência ou de radicalização do niilismo. Tal relação não é fortuita. Ora, na psicanálise a melancolia e a morte apresentam uma ligação estreita, oferecendo a meu ver perspectivas teóricas auspiciosas de aprofundamento de uma tradição que podemos reportar a Kant - sem aqui alimentar obviamente intenção de empreender qualquer forma de genealogia. Refiro-me aqui muito especificamente ao Luto e Melancolia, porém, é claro que o tema pode ser também trabalhado através de textos como 0 Mal-Estar na Civilização. Em oposição ao sentimento de luto, em que a perda de um "objeto" amado não compromete a integridade da individualidade, a melancolia é aqui considerada uma patologia que consiste na dificuldade de realização do trabalho de aceitação desta perda, dificuldade que se manifesta como sentimento de autodepreciação, rebaixamento de si. Que o mundo perca suas cores e sabores é, para Freud, uma decorrência natural de nossa experiência do desaparecimento de algo especialmente valorizado, amado, quer esse algo seja um ideal, um emprego, ou um ente querido. Preocupante para ele é que o trabalho do luto seja postergado indefinidamente, que outros "objetos" não venham a substituir em um devido tempo de sofrimento aquele que é centro de nosso investimento emocional (Freud, 1917: 2).

Sob o manto da autodepreciação melancólica, argumenta Freud, existe um impulso agressivo em relação ao objeto de investimento emocional que não encontrou, por alguma razão, possibilidade de ser suficientemente elaborado. Desde a antiguidade clássica, a observação de impulsos agressivos, destrutivos, de ódio, e, ao mesmo tempo, de tristeza, rebaixamento de si, faz parte da sintomatologia do que amplamente tem se denominado melancolia através dos séculos. A novidade em Freud, todavia, é a possibilidade de relacionar esses dois conjuntos de sentimentos polares em um todo compreensível. Toda emoção intensa guarda em si contracorrentes que a tornam fundamentalmente ambígua e, para Freud, é importante que essa ambiguidade seja reconhecida. O melancólico, todavia, é aquele que não teve a oportunidade de elaborar a agressividade que implicitamente sustenta com relação a um objeto decisivo de sua afeição. Essa agressividade retornaria ao eu num impulso autodestrutivo que poderia, em última instância, resultar em uma ação suicida. A agressividade não elaborada com respeito ao objeto de afeto retornaria na forma de tal impulso.

16 A hipótese que oferecemos é precisamente que, na modernidade, a constituição de uma narrativa da subjetividade, em torno da qual a psicanálise gira, é recorrentemente 
associada ao sentimento melancólico. Se entendermos o sujeito moderno como uma questão existencial, e não meramente ética ou epistemológica, diríamos que, mais que primordialmente uma experiência da ordem da razão, o espelho sobre o qual a cultura moderna retorna sempre a subjetividade é a melancolia. É desta perspectiva que ela se torna significativa, ou seja, quando esse sentimento nos retorna o sujeito como questão, mas também como possibilidade de resposta.

Na Crítica do Juízo, Kant chega a uma conclusão semelhante ao discorrer sobre o sentimento do sublime. $O$ sublime é originalmente um sentimento doloroso em que nos confrontamos com nossa insignificância diante da evidência de um mundo absoluto em sua infinitude. Sentir-se aniquilado é o primeiro e doloroso momento do sentimento do sublime, e, no entanto, é através dele que descobrimos nossa capacidade para transcender nossa condição finita, é através desse desconforto que encontramos a evidência estética de nossa disposição para a razão. Kant, assim, oferece um elemento fundamental para entender aquilo que Freud considera ambíguo na melancolia, ou seja, entendemos como o sofrimento que o sentimento do sublime desperta pode resultar em prazer: esta dor nos retorna a evidência estética do sujeito racional, finito, mas transcendente. Esta dor, este momento em que a língua trava, que o dizível é colocado em questão, é a própria experiência estética da centralidade do sujeito na vida moderna. Mediante o sentimento do sublime, Kant nos aproxima de uma explicação desse momento em que a linguagem fica em estado de suspensão. E o que surge dessa dificuldade é a experiência existencial da centralidade do sujeito.

18 A contrapartida da constituição de uma cultura de sujeitos, diante dos quais os objetos são concebidos como infinitamente controláveis pela razão, é precisamente o estabelecimento de um hiato intransponível entre esses dois mundos. 0 prazer atrabiliário consiste em, ao lamber suas próprias feridas, encontrar a possibilidade de estruturação de sua subjetividade como núcleo de estabilidade existencial mínima. $\mathrm{E}$ essa privatização da vida social, esse silêncio e inapetência que caracterizam o melancólico, são aspectos fundamentais da vida moderna. Por tudo isso, parece-nos sensata a argumentação que oferece Harvey Ferguson (2005: 26): "A filosofia moderna, particularmente em Descartes, Kant e Hegel, pressupôs a melancolia da vida moderna como condição permanente, e incorporou isso em suas reflexões, e assim fazendo domesticou o gênio subversivo que aderia a todo caso de "pesar sem causa» [...]. A melancolia moderna, enlutada, pesada e tonta como a infinitude, também está carregada com a lucidez metafísica da depressão".

Se Simmel nos diz que, diante da dinâmica caótica da vida moderna, o indivíduo precisa constituir um núcleo duro de subjetividade que lhe permita não ser digerido pela aceleração das grandes cidades, afirmamos aqui, numa linha de raciocínio afim, que a melancolia é o próprio investimento propiciador dessa narrativa moderna que é a subjetividade. Neste contexto cultural, significar o sofrimento melancólico é um ato de enorme sentido existencial, pois esse ato garante a própria "reflectividade" narcísica sem a qual uma sociedade dos sujeitos parece incompreensível.

20 Entre o moderno sujeito melancólico e o indivíduo depressivo que encontramos na contemporaneidade, devidamente estabilizado por antidepressivos e ansiolíticos, porém, há uma diferença que deve ser observada. Ora, é precisamente o investimento no sofrimento melancólico e na sua significação que parece ser negado nesse segundo caso. 0 melancólico dá sentido ao seu sofrimento para se constituir enquanto sujeito. 


\section{Falar o sofrimento para não transformá-lo em dor}

21 Sob condições modernas, o mergulho melancólico, o caráter narcisista de sua sintonia com o mundo, está associado de modo inextricável à elaboração da subjetividade. Esse mergulho já significa em alguma medida a elaboração de um núcleo de "segurança ontológica" a partir do qual o indivíduo poderá sobreviver à "tragégia da vida moderna", como diz Simmel, à ameaça de invasão da vida íntima pela aceleração, pelo excesso de estímulos da vida urbana. A saída psicanalítica se contrapõe a esse emudecimento de um modo curioso. Ora, se por um lado seu caráter confessional testemunha um desejo de se opor a tal silenciamento, na medida em que procura trabalhar uma significação para o sofrimento, por outro lado a psicanálise toma acriticamente a dinâmica melancólica $e$ subjetivista que torna possivel entender esse sofrimento como algo privado. Sob essa perspectiva, podemos entender o sofrimento como problema íntimo. o sujeito, bem como o humano, diria Foucault, são categorias históricas que não devem ser tomadas como algo dado. Há no discurso psicanalítico, portanto, a esperança de transformar a dor em um sofrimento significativo, mas, ao mesmo tempo, esse trabalho de significação é subjetivado e o limite de tal trabalho, por seu turno, é a dor.

Ainda que uma diferenciação entre dor e sofrimento seja em grande medida pedagógica, eu diria que a dor é sempre algo incomunicável ao outro. Trata-se de algo puramente biológico que nem sequer podemos recordar propriamente. Ela se localiza na concretude do corpo e como tal não pode ser objeto de compartilha, daí a dificuldade de rememorá-la como tal. A palavra sofrimento, por outro lado, possui uma ressonância claramente social; ela nos remete a algo, uma imagem que podemos compartilhar. Dolor etimologicamente nos leva a um beco sem saída. Sofrimento, sofrer, não: sufferrere significa estar sob o peso de algo (su [sob] ferre [carregar]). As formas de sofrimento remetem sempre, portanto, a uma imagem, a um símbolo que pode ser objeto de compartilha social. Deste modo, não há como calar o sofrimento sem transformá-lo em dor. Se o sofrimento é tratado como algo privado no contexto psicanalítico, e, neste sentido, como prenúncio das dores que as terapias bioquímicas buscarão silenciar, não há dúvida que sua estratégia implica, por outro lado, num falar o próprio sofrimento e não calar.

Creio ser possível associar a psicanálise, tanto de uma perspectiva histórica quanto epistemológica, a uma longa tradição que postula a tragédia como verdade humana fundamental. Do ponto de vista epistemológico, o falar psicanalítico se aproxima do trágico de um modo simples. "A tragédia é o lugar de um pensar que incomoda, lugar em que o mito que organiza a polis é posto sob uma luz na qual fica exposta sua ambiguidade fundamental. Sob essa luz, percebemos que o mito é um nó que amarra verdades tensas e contraditórias" (Ferreira e Miranda, 2011: 235 e 236). Se o mito é aquilo que funciona apenas enquanto sua dinâmica permanece emudecida, a tragédia nos proporciona precisamente uma experiência estética que coloca o mito em uma certa epoché, e, consequentemente, desfaz as pretensões de naturalização que conferem ao mito um sentido político.

Por outro lado, uma metafísica da subjetividade ainda preside as preocupações de Freud. Organicamente ligada a um projeto de controle, disponibilização, do mundo e do próprio ser humano, a categoria "subjetividade" sempre nos remete ao emudecimento do niilismo. Poderíamos afirmar que a privatização da antropodiceia sob a forma de investimento subjetivo, em última instância, está mais próxima da forma como o 
judaísmo e o cristianismo dão significado ao sofrimento. A verdade desta tradição é a transparência e a proporção de uma razão que a tudo deve presidir, mesmo quando a centralidade dessa razão parece, no caso da psicanálise, ser deslocada pelos conteúdos do inconsciente: Jó deve ser recompensado pelos seus infortúnios, Abraão por sua obediência inabalável, os justos devem alcançar o Reino de Deus, o sofrimento neurótico deve ser colocado em proporção pelo trabalho terapêutico. A busca de proporção entre intenção e resultados, entre boas ações e recompensas, por outro lado, é algo completamente estranho ao pensamento trágico e, nesse sentido, também a centralidade que a subjetividade alcança no mundo moderno.

Na tradição trágica, por outro lado, o sujeito é visto como uma categoria que promove, potencializa a dinâmica niilista que, por fim, e inevitavelmente, alcança a própria linguagem. Sobre isso deverei ainda falar, pois entendo que a importância hoje alcançada pela psicofarmacologia nas sociedades do conhecimento, da informação, a própria possibilidade de desenvolvimento deste campo científico, deve ser remetida ao contexto mais amplo no qual o capitalismo finda por instrumentalizar a própria linguagem. Há entre esse processo e a constituição de uma metafísica do sujeito uma relação inequívoca que se funda na mobilização técnica constante do real. Não se trata aqui, portanto, de uma guerra contra o uso de substâncias psicoativas, mas de entender como, a partir de que dinâmica cultural, estas substâncias puderam alcançar uma posição tão central nas sociedades contemporâneas.

\section{A língua quando emudece: a medicalização do sofrimento como sintoma cultural mais amplo}

Por tudo quanto foi exposto, a linguagem é um ponto crucial de nossas preocupações teóricas. Trata-se, antes de tudo, de uma reflexão sobre o lugar da fala diante da emergência de uma nova geração de medicamentos psicoativos e de terapêuticas, a estes estreitamente associados, que propõem um tratamento do mal-estar contemporâneo em que a importância da fala é posta em questão. É preciso, todavia, entender que essa forma de abordar o sofrimento deve ser entendida como fortemente discursiva. Como entender essa proposição aparentemente contraditória? Se recorrermos mais uma vez ao que aqui chamamos de tradição trágica para interpretarmos essa dificuldade, constataremos ali um diagnóstico das sociedades contemporâneas que indica o empobrecimento da linguagem por um certo positivismo científico, empenhado em eliminar toda discussão semântica como um empecilho à plena universalização de um conhecimento objetivo. É esta visão, este discurso, que prevalece hoje quando a psiquiatria busca reduzir o sofrimento a efeitos passíveis de serem tratados de modo objetivo. É necessário que reportemos a tendência contemporânea à medicalização, de um modo geral, e a tendência ao consumo de antidepressivos, ansiolíticos etc., a este movimento mais amplo que é produzido pela ciência moderna. E, assim, perguntamos: que discurso temos diante de nós?

Talvez a análise mais radicalmente crítica daquilo que a linguagem vem se tornando na sociedade da informação seja fornecida por Heidegger. A cibernética vem transformando vários campos da tecnociência em um terreno marcado pelo desejo de constituir instrumento linguístico não-ambíguo, que venha a viabilizar performances técnicas céleres. Silenciada de suas ambiguidades essenciais, no entanto, a linguagem resultaria empobrecida. Que esquecimento fundamental essa concepção de linguagem 
promove? "Não falamos simplesmente a linguagem. Mas a partir da linguagem. Isso só nos é possível porque já sempre pertencemos à linguagem. 0 que nela escutamos? Escutamos a fala da linguagem" (Heidegger, 1998: 203). Constatar isso é conduzir a questão da verdade para o terreno da finitude, é recusar a posição transcendente a partir da qual a tecnociência pretende conceber a fala, a linguagem, como um mero meio de exprimir pensamentos, de garantir instruções precisas, performances eficientes. É precisamente essa última possibilidade da linguagem, a linguagem instrumentalizada, tornada algo a serviço de performances eficientes que temos diante de nós ao menos desde que a teoria da informação, a cibernética se colocou como paradigma hegemônico das ciências.

A linguagem técnica, ou seja, a linguagem a serviço da performance, dos fluxos ininterruptos e eficientes de informação busca expurgar de si toda tensão, aqui compreendida como ruído. Seu empobrecimento está ligado àquilo que ele chama de "tédio profundo" na cultura pós-guerra, ou seja, um esvaziamento da possibilidade de significação em nome da execução de tarefas, o niilismo levado às suas últimas consequências. Vivemos na iminência da irracionalidade do real, cuidando sempre dos sobressaltos emocionais que resultam de vivências desconexas. Sofremos a impossibilidade de constituir alguma forma de antropodiceia. o psicofármaco não é causa nem consequência desse estado de coisas, desse empobrecimento. Usando o jargão weberiano, poderíamos afirmar que há uma afinidade eletiva entre o tratamento bioquímico das emoções e o niilismo radical em que a sociedade do consumo nos mergulha. A civilização do "verbo" é silenciada, cala. Ou, o que resulta no mesmo, somos capturados numa verbosidade oca, na intimidade de aeroporto, na dor que não pode saber de si. Há algo de preocupante aqui quando consideramos com George Steiner (2010: 21): "La primauté de la parole, de celle qui peut être parlée et communiquée par le discours, est caractéristique du génie grec et judaïque, et elle a été transmise à la chrétienté. La conception classique et chrétienne du monde s'efforce d'accorder réalité et maîtrise à la chrétienté."

Steiner propõe-nos uma reflexão interessantíssima sobre as implicações linguísticas que decorrem de ter a matemática passado a constituir, a partir do século XVII, o paradigma das ciências modernas. Para Steiner, o desenvolvimento da matemática posterior a Leibniz encaminha-nos paulatinamente para a indizibilidade, para a impossibilidade de enunciação verbal. O cálculo diferencial ou integral, as operações com números complexos se colocam para além da possibilidade da verbalização. Isso significa, por exemplo, que as operações subjacentes à simples atividade computacional pressuposta na escritura deste texto é intraduzível para a experiência humana (Steiner, 2010: 25). Steiner se pergunta com que autoridade o humanismo continuaria a pretender legitimidade se a esfera da palavra, do verbo, tem perdido paulatinamente importância diante da elegância e eficiência da matemática.

Se, no passado recente, essa dor cultural, que resulta da dificuldade em encontrar uma antropodiceia, sentido, para a existência numa sociedade que já não precisa de qualquer ethos que legitime suas dinâmicas econômicas e políticas, essa tragédia, como afirma Simmel, poderia encontrar paliativo numa narrativa subjetiva, hoje isso já parece se distanciar de nosso horizonte cultural. Entre o sofrimento melancólico e o trabalho da subjetivação se coloca o fármaco, que evidencia a precariedade da estratégia subjetivadora. Ora, a palavra é o suporte sobre o qual um trabalho de significação poderia ser empreendido pelo sujeito, pelo melancólico - e precisamente 
ali onde o seu sentido parece ser colocado em suspenso. Por tudo o que dissemos, esse suporte encontra-se desestabilizado pela matematização da realidade, pela tecnociência. Sem um reestabelecimento da palavra, todavia, como podemos conceber uma alternativa cultural que não represente adequação às dinâmicas empobrecedoras do capitalismo?

Porém, falar é muito mais difícil do que parece. Em que medida os elementos trágicos de nossa cultura, e que a psicanálise representa de modo ambíguo, poderão nos oferecer a esperança de uma alternativa a isso que chamamos, com Benjamin, "pobreza da experiência"? Em que medida tais elementos são compatíveis com a oferta de soluções químicas que não podemos desprezar? Longe de querer responder essas questões, esse texto pretendeu levantá-las.

\section{BIBLIOGRAFIA}

ADORNO, T. W. \& M. Horkheimer (1985), Dialética do Esclarecimento, Rio de Janeiro, Jorge Zahar.

BENJAMIN, W. (1984), A Origem do Drama Barroco Alemão, São Paulo, Editora Brasiliense.

CONTI, N. A. (2007), História de la Depresión. La melancolía desde la Antigüedad hasta el Siglo XIX, Madrid, Pollemos.

D’ÁVILA, T. (2010), Livro da Vida, São Paulo, Penguin-Cia das Letras.

EHRENBERG, A. (1995), L'individu incertain, Paris, Hachette Littératures.

FERGUSON, H. (2005), Melancholy and the Critique of Modernity, Soren Kierkegaard's religious psychology, London, Routledge.

FERREIRA, J. e A. R. Silva (2011), “A Experiência Contemporânea da Nudez”, Revista Crítica de Ciências Sociais, V. 92, pp. 147-167.

FERREIRA, J. e E. Miranda (2011), “Consumo de psicofármacos: entre o cuidado de si e a sintetização da catarse”. In Ferreira, J. e A. Scribano (ed.) Corpos em Concerto. Recife, Editora da UFPE.

FOUCAULT, M. (2002), Ditos e Escritos. Vol. 1. Problematização do sujeito: psicologia, psiquiatria e psicanálise, Rio de Janeiro, Editora Forense-Universitária.

FREUD, S. ([1915] 1917), Duelo y Melancolía, Librodot.com.

GROB, G. N. e A. Horwitz (2010), Diagnosis, Therapy, and Evidence: conundrums in modern American medicine, New Brunswick, Rutgers University Press.

HEIDEGGER, M. (1998), A caminho da Linguagem, Petrópolis, Editora Vozes.

KANT, I.(2007), Critique of Judgement, Oxford, Oxford University Press.

KIRSCH, I. (2010), The Emperor's New Drugs, Exploding the Antidepressant Myth, New York, Basic Books.

PATOCKA, J. (1996), Heretical Essays in the Philosophy of History, Chigago, Open Court. 
RADDEN, J. (2000), The Nature of Melancholy, From Aristotle to Kristeva, Oxford, Oxford University

Press.

STEINER, G. (2010), Langage et silence. Paris, Les Belles Lettres.

\section{NOTAS}

1. Comunicação apresentada no V Congresso Ibero-Americano de Pesquisa Qualitativa em Saúde - Circulação de Saberes e Desafios em Saúde, realizado em Lisboa entre 11 e 13 de Outubro de 2012.

2. Dados do relatório Health at a Glance 2011 - OECD Indicators.

3. "O que nos fascina, sempre de novo, na destruição do tirano é a contradição entre a onipotência e a abjeção de sua personalidade, por um lado, e a convicção da época quanto à força sacrossanta de sua função, por outro" (Benjamin, 1984: 95).

\section{RESUMOS}

O ensaio que se segue procura analisar o estatuto do sofrimento na contemporaneidade diante da disponibilidade de psicofármacos de última geração. Para isso restringimos a ideia ampla de sofrimento num conceito mais específico, i. e., o de melancolia. Tomando a melancolia como momento existencial fundamental para o estabelecimento de uma dinâmica moderna da subjetividade, postulamos que o psicofármaco age de modo a tornar supérfluo o trabalho de significação implícito em tal dinâmica. O que torna esse trabalho desnecessário não é apenas um esvaziamento da subjetividade, da interioridade, como estratégia de significação existencial, mas o próprio falar que, reduzido à condição de instrumento de performance, já não se permite colocar de modo radical a questão do sofrimento humano.

The following essay intends to analyse the contemporary statute of suffering in face of the availability of last generation psychopharmaca. Bearing in mind this general goal we restrict the broad idea of suffering into a more specific concept, i. e., that of melancholy. Taking melancholy as an existential and fundamental moment for establishing the modern dynamics of subjectivity, we postulate that psychopharmacon acts as to make superfluous the labor of signification which is implicit in such a dynamics. What makes unnecessary such a work is not only the emptying of subjectivity, of interiority, as a strategy of existential signification, but the very speech itself which, reduced to the condition of a tool at the service of performance, does not allow itself to radically formulate the question of human suffering.

\section{ÍNDICE}

Keywords: melancholy, psychopharmacon, language

Palavras-chave: melancolia, psicofármaco, linguagem 